\title{
Starved for attention
}

Previously published at www.cmaj.ca

\lceil NICEF estimates that 195 million children suffer from malnutrition; every six seconds, a child dies from malnutrition-related causes. These staggering figures are difficult to fathom. But a powerful series of seven multimedia documentaries, Starved for Attention (www.starved forattention.com), puts faces and stories to these facts. The documentaries are an innovative collaboration between Médecins sans Frontières (MSF), which has long borne witness to health-related atrocities, and VII Photo Agency comprised of seven top photojournalists dedicated to communicating the most pressing issues of our time.

These video and still-photograph documentaries celebrate a few successful programs, such as some in Mexico and the US, and expose the ongoing suffering from this largely ignored and "invisible epidemic" in other countries.

The latter stories are heart-wrenching — and maddening. The solutions, such as nutrient-rich food supplements, are available; it is the political will that appears to be lacking. Most of us remember the images of starving children in war-torn Biafra in 1969. Malnutrition is something different: it is widespread and largely invisible. These are the stories of three-year-olds

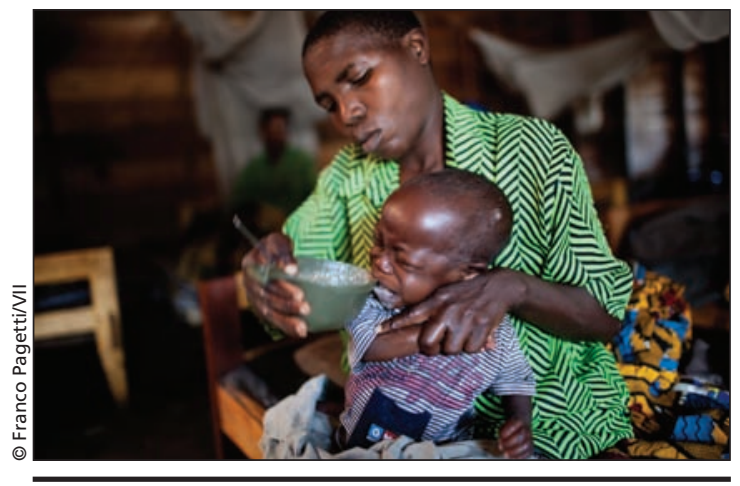

The Democratic Republic of Congo is incredibly fertile, yet thousands of children are malnourished.

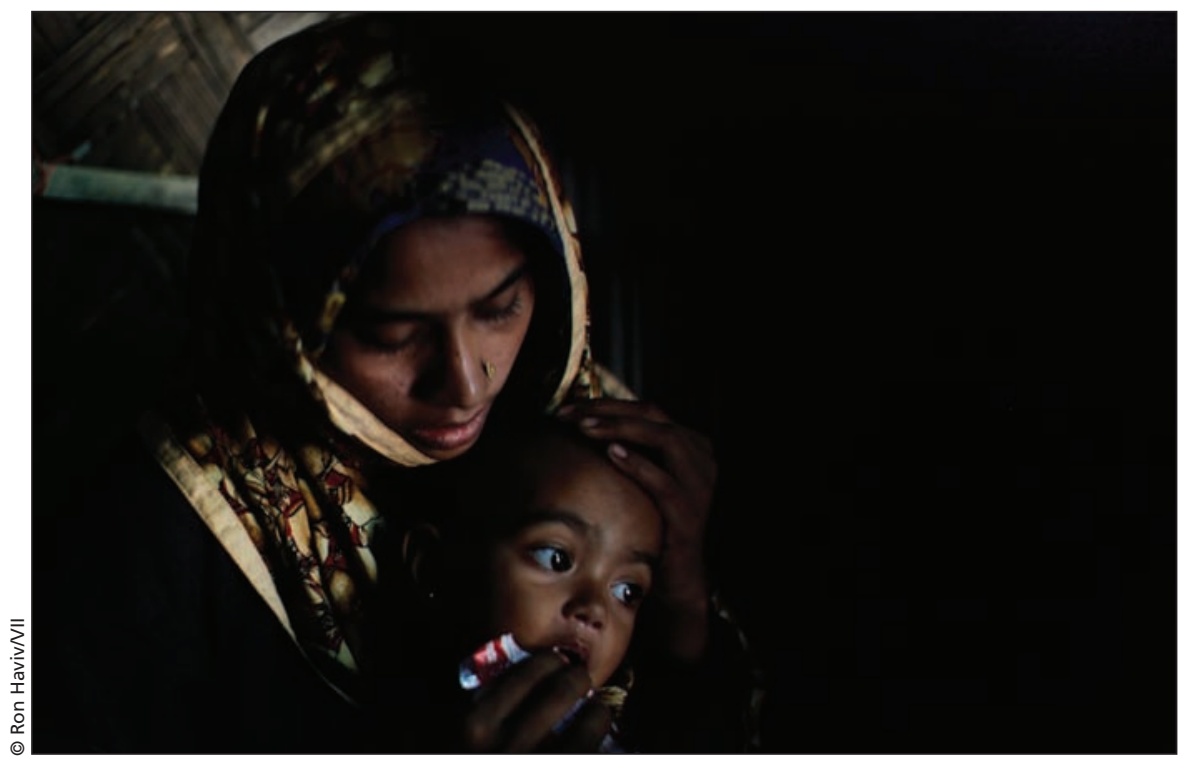

In Bangladesh, experts estimate that half the children under five years old are underweight.

who cannot speak, four-year-olds who cannot walk.

Some of the documentaries are told from the perspective of MSF staff, such as those who work at a 35-bed hospital in Djibouti, an African country with 60 to 70 per cent unemployment and little arable land. In 2009, they treated 1700 children, but so much more is needed according to doctors. This reality is echoed in an MSF project in India, where one-third of the world's malnourished children live.

One of the most poignant documentaries follows a single mother in Burkina Faso whose son is malnourished. She will go without eating for a week, so she can feed her children.

In some areas of Bangladesh, where an estimated eight million children under five are underweight, malnutrition is considered a "Terrifying Normalcy." This acceptance is in many ways the most distressing aspect of these documentaries.
However, there are successes, such as Mexico's Opportunidas program, which brings fortified milk powder to pregnant women and children under three and brings nutrition education to remote states. Also featured is the US Women, Infants and Children program, which provides vouchers for nutrition-rich foods for nine million. It's heartening to see that MSF and VII Photo Agency had the courage to portray malnutrition in the industrial world — and the failings of its aid programs. The second part of the US documentary slams the US Food Aid program for sending homegrown corn-soybean meal, which is not nutritious enough for growing children.

The documentaries and supporting materials are available online, though the small reverse type makes for difficult reading. Still the message is clear: Starved for Attention is a powerful tool for raising awareness.

\section{Barbara Sibbald BJ}

Deputy Editor, Analysis and

Humanities

CMAJ 